\title{
"Allá en La Bonga viví yo". Expresiones de memoria colectiva sobre los efectos del conflicto armado en Colombia
}

\author{
"Allá en La Bonga viví yo". Expressions of collective memory on the effects of the \\ armed conflict in Colombia
}

\author{
Claudia Beltrán Romero \\ Universidad Autónoma del Caribe, Colombia \\ https://orcid.org/0000-0002-7093-9051 \\ David J. Luquetta Cediel \\ Universidad Autónoma del Caribe, Colombia \\ https://orcid.org/0000-0002-6541-1973 \\ Clemencia Rodríguez Romero ${ }^{3}$ \\ Temple University, Estados Unidos \\ https://orcid.org/0000-0002-3045-595X \\ Martha Romero Moreno \\ Universidad Autónoma del Caribe, Colombia \\ https://orcid.org/0000-0002-0190-7240 \\ Luis Navarro Diaz 5 \\ Universidad Autónoma del Caribe, Colombia \\ https://orcid.org/0000-0001-9397-8494
}

1 Magíster en Comunicación, socióloga, docente del Programa de Comunicación Social de la Universidad Autónoma del Caribe, adscrita al grupo de investigación: Comunicación y Región. Correo electrónico: claudiabeltranr@hotmail.com

2 Doctor en Ciencias Sociales, antropólogo. Correo electrónico: david.luqueta@uautonoma.edu.co

3 Doctora en International Telecommunications, comunicadora social, profesora de la Temple University. Correo electrónico: tug84599@temple.edu

4 Estudiante de Doctorado en Comunicación, magíster en Comunicación, comunicadora social periodista, licenciada en Lenguas Modernas, docente del Programa de Dirección y Producción de Radio y Televisión de la Universidad Autónoma del Caribe, adscrita al grupo de investigación: Área de Broca: Medios, Lenguaje y Sociedad. Correo electrónico: martha.romero17@uac.edu.co

5 Doctor en Ciencias Sociales, comunicador social y filósofo, docente investigador del Programa de Dirección y Producción de Radio y Televisión de la Universidad Autónoma del Caribe, adscrito al grupo de investigación: Área de Broca: Medios, Lenguaje y Sociedad. Correo electrónico: rnavarrod@hotmail.com 
Artículo de investigación

Fecha de recepción: 30 de agosto de 2018 Fecha de aceptación: 26 de octubre de 2018

\section{Para citar este artículo}

Beltrán Romero, C., Luquetta Cediel, D. J., Rodríguez Romero, C., Romero Moreno, M. y Navarro Díaz, M. (2019). “Allá en La Bonga viví yo”. Expresiones de memoria colectiva sobre los efectos del conflicto armado en Colombia. Campos en Ciencias Sociales, 7(1), 17-42. DOI: : https://doi.org/10.15332/25006681.4523 


\section{Resumen}

El siguiente artículo presenta un análisis de la información pragmática contenida en una composición musical, de autoría de una persona que sufre el desplazamiento forzado de la vereda La Bonga (San Basilio de Palenque, Bolívar, Colombia). El texto de la canción se constituye en un dispositivo cultural como vehículo de la memoria colectiva de esta comunidad, expresando el deseo de retorno a su territorio. El artículo propone una mirada desde lo conceptual y lo metodológico de las narrativas que surgen como formas de expresión y resistencia de la gente en el contexto del conflicto social armado en Colombia.

Palabras clave: análisis pragmático, conflicto armado en Colombia, desplazamiento forzado, memoria histórica, formas simbólicas, vereda La Bonga (Montes de María).

\section{Abstract}

The following article presents an analysis of the pragmatic information contained in a musical composition, written by a person who suffers the forced displacement of La Bonga rural area (San Basilio de Palenque, Bolívar, Colombia). The lyrics of the song constitutes a cultural device, as a vehicle for the collective memory of this community, expressing the desire to return to its territory. The article proposes a conceptual and methodological view of the narratives that emerge as forms of expression and resistance of the people in the context of armed social conflict in Colombia.

Keywords: pragmatic analysis, armed conflict in Colombia, forced displacement, historic memory, symbolic forms, La Bonga rural area (Montes de María). 


\section{INTRODUCCIÓN}

El análisis del discurso pretende mirar cómo en los mensajes hay marcas que evidencian rasgos lingüísticos e ideológicos de sus creadores y por ello existe una variedad metodológica que puede enmarcarse como tal. Una de esas aproximaciones es el análisis pragmático de la información contenida en una forma simbólica como posibilidad de estudios que pretenden una aproximación al mundo experimentado por el hablante, asociado a un momento y a un territorio. El texto analizado es la canción "Allá en la Bonga viví yo", que se aborda como un artefacto cultural contenedor de memorias sobre el desplazamiento forzado de la población de la vereda La Bonga en el marco del conflicto armado colombiano.

En primer lugar, se presenta el contexto sociohistórico y geográfico que subyace al texto analizado, para dar luego paso al análisis de la información pragmática del mismo, que permitirá un acercamiento a los contenidos de las memorias colectivas de esta población.

\section{Tierra y conflicto social armado en los Montes de María}

Hasta el momento, los estudios que analizan las causas y la permanencia del conflicto armado en Colombia confluyen al sugerir que uno de los factores desencadenantes del mismo ha sido el control territorial. "La apropiación, el uso y la tenencia de la tierra han sido motores del origen y la perduración del conflicto armado" (Centro Nacional de Memoria Histórica, 2013). A partir de allí, entran a jugar en diversas hipótesis otros factores políticos, sociales, culturales, criminales, etc.

Justamente, el control del territorio ha sido el factor determinante del conflicto armado en la subregión de Montes de $\mathrm{María}^{6}$, que ha sido una de las zonas que más

6 La Región de Montes de María está ubicada en la costa norte de Colombia, tiene una extensión de 6.466 km². Según el censo de 2005, habitan allí aproximadamente 438.119 personas, distribuidas en 15 municipios: Ovejas, Chalán, Colosó, Los Palmitos, Morroa, San Onofre, Tolú Viejo y San Antonio de Palmito, en el departamento de Sucre; y El Carmen, María La Baja, San Juan Nepomuceno, San Jacinto, Córdoba, Zambrano y El Guamo, en el departamento de Bolívar (Dane, 2005). 
ha sufrido por este conflicto en el país. Los procesos de apropiación y expropiación de tierras llevaron a grandes brechas sociales en los Montes de María, dejando la tierra en manos de un reducido número de familias que poseían enormes extensiones de tierra, disfrutaban los beneficios de la integración al Estado central y se beneficiaban de los mercados nacionales e internacionales (Rodríguez, 2008).

En ese mismo sentido, el informe elaborado por De los Ríos, Becerra, Oyaga y Sáenz (2012), señala que una de las características de la zona es el alto grado de concentración de la tierra, cuya magnitud medida con el coeficiente de Gini ${ }^{7}$ evidencia una enorme desigualdad en la distribución de la misma: El Guamo con un indicador de 0,84, María La Baja con 0,78 y Zambrano con 0,7, entre otros.

Además, se afirma que estas desigualdades relacionadas con la tierra conllevaron a una agudización del conflicto en la región desde la década de los ochenta, encontrándose presencia de grupos subversivos como el PRT (Partido Revolucionario de los Trabajadores), el ELN (Ejército de Liberación Nacional), la CRS (Corriente de Renovación Socialista) y algunos frentes de las FARC-EP (Fuerzas Armadas Revolucionarias de Colombia - Ejército del Pueblo), quienes pretendieron tomar partido en las luchas campesinas por la redistribución de la tierra, lideradas desde los años sesenta por la Asociación Nacional de Usuarios Campesinos (ANUC).

Adicionalmente, hacen referencia a una serie de evidencias documentadas que vinculan a los terratenientes con el principio de lo que más tarde sería el surgimiento del paramilitarismo, cuya presencia en los Montes de María llevó a la agudización del conflicto entre finales de la década de los noventa y el 2005.

Una de las evidencias que se ofrece, es la revelada en versión libre de mayo 16 de 2007 ante fiscales de Justicia y Paz, según la cual, los hermanos Castaño Gil y Salvatore Mancuso, establecen alianzas con empresarios y políticos de la región de Montes de María, como fue el caso de Miguel Nule Amín propietario de la finca Las Canarias, con quien decidieron la conformación, en 1997, del bloque "Montes de

7 Número entre 0 (cero) y 1 (uno). Si se acerca más al 0 es indicador de mayor igualdad y si se acerca más al 1 indica mayor desigualdad en la distribución de los recursos. 
María”, una estructura armada que durante ocho años aplicó la máxima estratagema paramilitar de "quitarle el agua al pez", consistente en arrasar, desplazar y masacrar las poblaciones del entorno, para dejar sin bases sociales (quitarle el agua) a los grupos guerrilleros (el pez). Pero no solamente para eliminar a los guerrilleros, sino también para copar los territorios donde habitaron las poblaciones victimizadas y apoderarse de los negocios y las rutas del narcotráfico. Los responsables de ejecutar las acciones del grupo paramilitar en la zona fueron Edwar Cobos Téllez, alias "Diego Vecino", Diego Mercado Pelufo alias "Cadena" y Úber Bánquez Martínez alias "Juancho Dique".

Así, en algunos aspectos la declaración americana no avanzó como se esperaba, pero reconoce reclamaciones significativas para los pueblos originarios. Representa un consenso muy importante y difícil de alcanzar y muestra la opinio iuris americana al respecto. Además, surgiendo en el ámbito de la OEA, tiene un marco de presión moral y política para su cumplimiento. No obstante, es solo una declaración no vinculante y sin mecanismos eficaces de control. Se adoptó hace muy poco tiempo, por lo que sus efectos aún están por verse. En las últimas décadas ha habido un gran avance en el plano normativo; los esfuerzos deberían dedicarse ahora a su aplicación para que sean efectivos. Ante esto hay varios obstáculos por la falta de voluntad de los Estados.

\section{Vereda La Bonga}

Una de las víctimas directas de estas acciones fue la comunidad de la vereda La Bonga, corregimiento de San Basilio de Palenque en el municipio de Mahates (Bolívar). Ubicada geográficamente en una zona estratégica que interconecta a Mampuján ${ }^{8}$, Las Brisas 9 , San Pablo ${ }^{10}$, San Cayetano ${ }^{11}$ y San Basilio de Palenque. Esta población afrodescendiente, dedicada a la agricultura, cría de animales pequeños y a la fabricación de esteras de palma de iraca, sufrió un primer desplazamiento forzado

8 Corregimiento del municipio de María La Baja (Bolívar).

9 Vereda del municipio de María La Baja (Bolívar).

10 Corregimiento del municipio de María La Baja (Bolívar).

11 Corregimiento del municipio de San Juan Nepomuceno (Bolívar). 
en marzo de 2000, cuando 60 paramilitares al mando de alias "Cadena" obligaron a la comunidad del corregimiento de Mampuján a abandonar sus tierras y masacraron 11 personas en la vereda Las Brisas (De los Ríos et al., 2012) Tanto los desplazados de Las Brisas como los de La Bonga que salieron por temor, se asentaron en una vieja pista de aterrizaje del Instituto de Mercadeo Agropecuario (Idema), ubicada en el corregimiento de San Pablo, sin embargo muchos bongueros se devolvieron a los pocos días (Correa, 2005).

Figura 1. Panfleto del 5 de abril de 2001
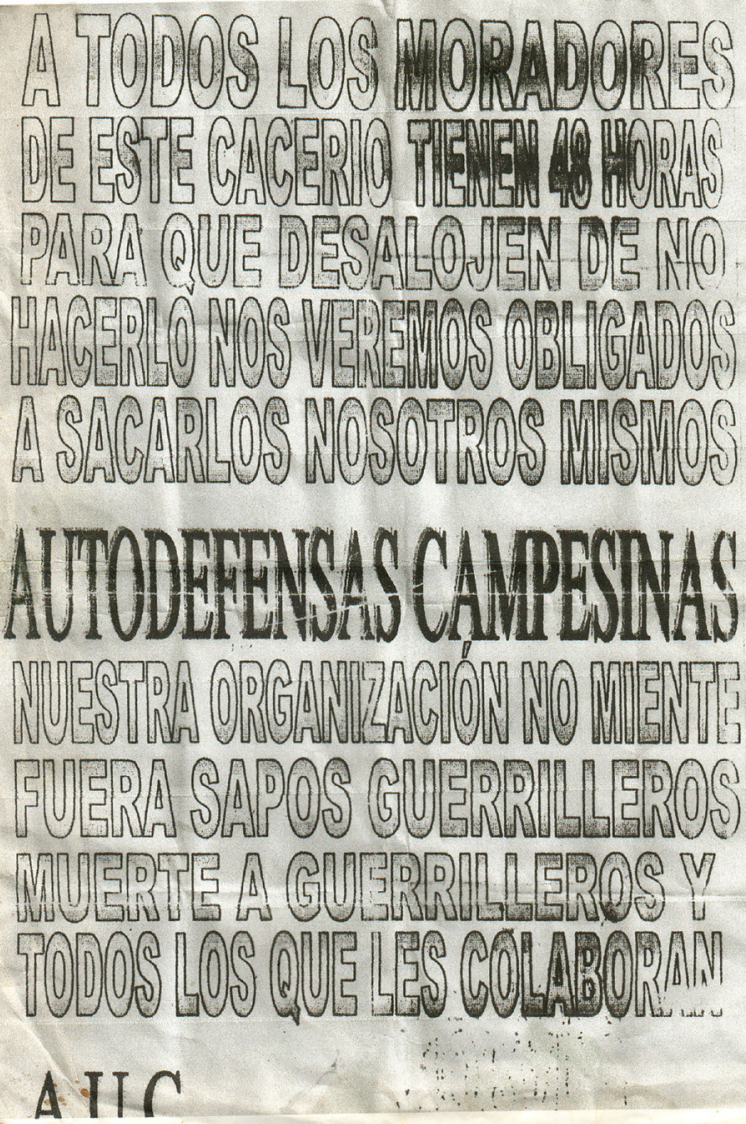

Fuente: archivo de la comunidad 
Aproximadamente un año después, el 5 de abril de 2001, paramilitares pertenecientes a este mismo bloque, llegaron directamente a la vereda La Bonga y repartieron panfletos amenazantes entre la población, dando un plazo de 48 horas para que la población abandonara el lugar (Figura 1); acción consecuente con la estratagema de "quitarle el agua al pez", es decir, quitarle las bases sociales a los grupos subversivos que tomaban a La Bonga como un corredor hacia la alta montaña, asumiendo que sus pobladores eran auxiliadores de la guerrilla.

En consecuencia, desde el 6 de abril de 2001 el total de las familias habitantes de La Bonga abandonaron sus viviendas, sus cultivos y sus animales, dividiéndose en dos grandes grupos. El primero, de 65 familias, se desplazó hacia el corregimiento de San Basilio de Palenque, distante a 12 kilómetros; y el segundo grupo, de 38 familias, se desplazó hacia el corregimiento de San Pablo del municipio de María La Baja, también en el departamento de Bolívar y distante 11 kilómetros de La Bonga.

El grupo de familias que se trasladó a San Basilio de Palenque se refugió durante 6 meses en condiciones de hacinamiento en el colegio de bachillerato (Institución Educativa Técnica Agropecuaria Benkos Biohó). Luego fueron reubicados en un terreno situado al sur de San Basilio de Palenque y que fue llamado "La Bonga de San Rafael”, en honor al sacerdote católico Rafael Castillo quien gestionó con diversas entidades la consecución del mismo.

Desde el momento mismo del desplazamiento, la comunidad de La Bonga ha venido reclamando ayuda humanitaria, reparación del daño causado y garantías para el retorno. Cinco años después de los hechos, el desplazamiento fue configurado legalmente como tal, según la Resolución n. ${ }^{\circ} 324$ del 12 de julio de 2006, emitida por la Alcaldía de Mahates, por medio de la cual se declaró zona de desplazamiento al territorio de la vereda La Bonga y zonas aledañas.

Hay que señalar que esta comunidad fue desplazada de su territorio acusada de ser auxiliadora de la guerrilla, pero sus tierras no les fueron arrebatadas, de manera que, con el fin de no perder su relación con el territorio abandonado y por razones económicas, algunos de los antiguos pobladores de La Bonga volvieron a trabajar sus 
tierras en jornadas diarias, cuyo recorrido les significa hasta 4 horas de ida y vuelta, en bestias o a pie, afectando la salud de los mismos; puesto que la economía de la zona no solamente se ha visto limitada por la alta concentración de la tierra y la presencia de actores armados, sino también por el abandono estatal (Aguilera, 2013).

\section{Memoria histórica del desplazamiento de La Bonga}

De acuerdo con la revisión sobre Halbwachs realizada por Lifschitz y Arenas (2012), este fue el primero en hablar de memoria como un fenómeno sociológico, diferenciando entre memoria social y memoria individual. La categoría de la memoria social, lo es por cuanto recordar siempre es un acto colectivo que implica, por un lado, que los otros nos estimulan el recuerdo, y por otro lado, que recordar es siempre recordar a los otros. En ese sentido, el hacer memoria, al involucrar actos de interacción y actualización de las interacciones pasadas, cumple la función de generar cohesión social, formando al decir de Halbwachs, las "comunidades afectivas".

Por su parte, Daniel Valencia en su editorial de la revista Conmemora (abril, 2014), nos recuerda que Jorge Luis Borges expresó en uno de sus poemas que "somos nuestra memoria", interpretándolo como que las experiencias y recuerdos que evocamos, no solamente nos definen, sino que determinan nuestro presente y futuro. Esta última es una sentencia que hay que atender con mucho cuidado al elegir qué recordar y cómo recordarlo.

Así mismo, construir la memoria del conflicto armado en Colombia, tal como es concebida por el Centro Nacional de Memoria Histórica (CNMH), constituye un trabajo fundamental para el esclarecimiento de los hechos y de los responsables de las violaciones a los derechos humanos, con el propósito de contribuir a la no repetición de las mismas. Pero también es una labor esencial para la reparación simbólica de las víctimas, al priorizar sus voces, dignificándolas y dándoles un lugar de importancia en la historia de la nación colombiana. Gonzalo Sánchez, director del CNMH, en el prólogo del informe " $\mathrm{B}$ asta ya! Colombia: memorias de guerra y dignidad" (2013), define la memoria como "una expresión de rebeldía frente a la violencia y la impunidad. Se ha convertido en un instrumento para asumir o confrontar el conflicto, o para ventilarlo en la escena pública" (CNMH, 2013, p. 13). 
En la misma línea, el CNMH presenta en su publicación Recordar y narrar el conflicto. Herramientas para reconstruir memoria histórica (2009), la necesidad de llevar a cabo ejercicios de memoria, entendidos como la forma de construcción de tejido social y además de identidades individuales, que es lo que se pretende evidenciar con el análisis de esta canción en el caso del desplazamiento que abordamos en este texto.

\begin{abstract}
[...] los procesos de elaboración de memoria histórica pueden convertirse en el terreno desde el cual se auspicia la formación de identidades individuales y colectivas más democráticas y responsables, que asumen con entereza tanto los actos de heroísmo y generosidad de los que han sido capaces como sus propios errores y desaciertos (p. 36).
\end{abstract}

Desde la perspectiva conceptual y en la dirección propuesta, hacer memoria sobre el caso de desplazamiento forzado sufrido por los pobladores de la vereda La Bonga, contribuye también a la cohesión social de una comunidad que por el mismo desplazamiento se ha ido fragmentando, rompiéndose el tejido social que constituía comunidad mientras estuvieron en el territorio.

\title{
“Allá en La Bonga viví yo"
}

Esta frase alude al título de una canción compuesta por Juan Herrera "El Futuro", nacido en La Bonga, desplazado y actualmente asentado en el barrio "La Bonga de San Rafael” en el corregimiento de San Basilio de Palenque. Compuso esta canción ante la solicitud de una estudiante universitaria ${ }^{12}$ que indagaba por la experiencia del desplazamiento en expresiones culturales. La composición fue elaborada en ritmo de bullerengue ${ }^{13}$, y denota la nostalgia de una vida que pierde sentido cuando se abandona la tierra, pero que se aferra a la esperanza del retorno.

12 María José Ayola, estudiante del Programa de Dirección y Producción de Radio y Televisión de Uniautónoma, desarrollaba en 2014 un documental sobre la situación de desplazamiento de la población.

13 Esta danza es efectuada solo por mujeres. Es quizás uno de los bailes en los cuales se destaca con mayor fuerza la ascendencia africana. Esta se pone en evidencia en los tambores, el palmoteo y el canto coral que acompańa su ejecución. Al parecer, surgió como una reacción cultural dentro del contexto ceremonial de las comunidades cimarronas, probablemente en el palenque de San Basilio. En esencia es una danza ritual que se realiza de manera especial cuando las jóvenes llegan a la pubertad. El bullerengue simboliza la fecundidad femenina, aunque no se 
La memoria no solamente habita en las mentes de las personas. Entre otros, también habita en los lugares, en los aromas, en los objetos, y en este caso en el canto, que es una forma local de narrativa de la memoria (Bayuelo, 2012). En esta dirección, se entiende la composición analizada como memoria objetivada en un artefacto cultural.

\section{Los objetos de la memoria como formas simbólicas}

Dado que toda práctica humana puede ser analizada desde la dimensión cultural, el análisis de esta composición musical como un artefacto de la memoria colectiva, implica concebirla como una forma simbólica. Una forma simbólica es una forma que contiene y expresa de manera implícita un conjunto de valores y representaciones del mundo, y tal como un libro, cuya distinción no está en el contenido sino en su forma simbólica, la composición musical como forma simbólica es finalmente una forma de pensar (Panofsky, 1932, citado por Melot, 2008).

Para ser analizada, una forma simbólica se entiende como portadora de información para los seres humanos, de la que se infieren sus sentidos y significados. Es decir, como un fenómeno significativo que a través del proceso comunicativo, se produce, circula y es apropiado por los sujetos sociales.

Para Mosterín (1993), la información contenida se expresa en tres dimensiones particulares: como información sintáctica, entendida como forma o estructura, como información semántica, como correlación entre dos objetos, en el cual uno dice algo sobre el otro, y como información pragmática, aquella que es capaz de cambiar el estado del receptor.

[...] la información en sentido pleno es la pragmática, que presupone la sintáctica como su condición misma de posibilidad. La forma de la señal puede estar en cierta relación con determinados receptores o agentes, siendo capaz

descarta que también en tiempos coloniales haya tenido connotaciones fúnebres (tomado de: Atlas de las culturas afrocolombianas. http://www.colombiaaprende.edu.co/html/etnias/1604/article-83214.html). 
de informarlos (cambiarlos) de tal manera que sus disposiciones conductuales se vuelvan distintas. En esa medida, la señal contiene información pragmática para esos receptores (pp. 21-22).

En síntesis, la información pragmática denota una relación entre un mensaje y un receptor, en la que el mensaje informa al receptor y por lo tanto induce en él ciertos cambios. El tipo de cambios o efectos que la información pragmática tenga sobre el receptor, depende del tipo de información. En este caso, Mosterín (1993) identifica tres tipos de información pragmática: a) información descriptiva o teórica, referida a los datos, al saber qué, b) información práctica o técnica, referida a las formas de hacer, a las habilidades y, c) información valorativa o evaluativa, referente a las preferencias, valores, actitudes, filias y fobias.

Por su lado, y partiendo de esta clasificación, Ariño (1997) complementa el anterior conjunto con la información prospectiva, que toma de Therborn (1987), cuando este señala que el funcionamiento social básico del proceso sometimiento-cualificación comprende tres modos básicos de interpelación ideológica: a) lo que existe y lo que no existe, b) lo que es bueno, correcto, justo, hermoso, agradable y sus contrarios y, c) lo que es posible e imposible, que en este caso, es la información prospectiva referida.

Todo esto, dentro de un contexto histórico y sociocultural y una intencionalidad, consideradas por Thompson (1990) como parte de los atributos de las formas simbólicas. Lo anterior implica que las formas simbólicas son, por un lado, producidas por agentes dotados con recursos y habilidades diversas, con una intencionalidad (consciente o inconsciente); y por otro lado, son marcadas por las condiciones sociales en las que se produjeron. Es decir, que están determinadas por el contexto social e histórico específico en que nacen.

En síntesis, este trabajo se interesa por la información pragmática de la composición musical que vehicula una parte de la memoria colectiva de la vereda La Bonga, en el contexto del conflicto social armado en Colombia. 


\section{Metodología}

El análisis de información pragmática de la composición musical se realiza con un enfoque cualitativo hermenéutico, buscando una aproximación al mundo experimentado por el hablante, asociado a un momento y a un territorio. La cuestión "es comprender tanto cómo se construye en la relación intersubjetiva el sentido, como cuál es, en su esencia, el despliegue de la subjetividad en la realización de este sentido" (Vargas, 2003, p. 7). Entendiendo que la subjetividad es una dimensión válida del conocimiento que permite comprender la experiencia vital de los sujetos, su cotidianeidad, describir los significados vividos, existenciales, develar las estructuras internas del mundo de la vida, explorar el significado del ser humano, conocer los significados que los individuos bongueros dan a sus experiencias y relaciones con el conflicto armado y el desplazamiento.

Desde esta perspectiva, resulta pertinente decir con Antony Giddens (1997) que el papel del investigador es hacer una "hermenéutica doble", en tanto que la comprensión de los fenómenos no solo depende del contraste de los datos con los referentes teóricos, en este caso la canción como forma simbólica que vehicula información pragmática, sino de tener consciencia de que estos datos ya están estructurados simbólicamente por los sujetos que los producen, y por lo tanto, la tarea metodológica consiste en interpretar lo ya interpretado por los sujetos, con el propósito de identificar lo significativo de la experiencia (Beltrán y Vega, 2012).

Por lo anterior, es preciso subrayar que los resultados del estudio no son generalizables a otros contextos sociales ni a poblaciones más amplias, ni siquiera de la misma región Caribe colombiana, sino que se dirigen a la comprensión de vivencias en un entorno específico, cuyos datos emergentes aportan al entendimiento del fenómeno en ese entorno.

\section{Procedimiento}

El análisis pragmático del texto identificará información descriptiva, información técnica, información valorativa e información prospectiva. En el proceso se hará 
uso de las siguientes preguntas orientadoras cuyas respuestas proveen cada tipo de información:

- ¿Qué dice el texto sobre el mundo de la vida de una persona que experimentó el desplazamiento forzado?

- ¿Cuáles son las habilidades requeridas para saber hacer en ese mundo experimentado?

- ¿Cuáles son las formas de valoración y la evaluación que se hace de ese mundo experimentado?

- ¿Qué futuro vislumbra el sujeto para ese mundo vivido; qué es deseable, qué es posible?

En las respuestas a las preguntas anteriores también estará, de manera transversal, la respuesta a la pregunta por las condiciones sociales en que ese texto fue producido.

\section{Corpus de análisis}

Como se ha mencionado, el corpus de análisis es la composición musical "Allá en La Bonga, viví yo", compuesta por Juan Herrera, cuyo nombre artístico es "El Futuro". Afrodescendiente, bonguero, campesino, padre, cantante y compositor de ritmos palenqueros, desplazado y sobreviviente cotidiano, que despliega sus esfuerzos para ser reconocido como artista. 


\title{
“Allá en La Bonga, viví yo”
}

\author{
I \\ Cuando yo vivia en La Bonga, \\ en casa de bahareque y sin luz, \\ las fiestas eran divinas, \\ porque eran hasta amanecer (bis)
}

\section{Coro}

Allá en La Bonga, viví yo,

quiero retornar, sí señor.

Allá en La Bonga, vivi yo,

quiero retornar, si señor.

\section{II}

No tenía celular,

tampoco televisor,

aunque ustedes no lo crean,

me sentía mucho mejor (bis).

\section{Coro}

Allá en La Bonga, viví yo,

quiero retornar, sí señor.

Allá en La Bonga, vivi yo,

quiero retornar, si señor. 


\section{III}

Vivía de mi cultivo,

eso mi padre me enseñó,

con eso me sustentaba,

una riqueza tenía yo (bis).

\section{Coro}

Allá en La Bonga, viví yo, quiero retornar, sí señor.

Allá en La Bonga, viví yo, quiero retornar, sí señor.

V

Quiero vivir en La Bonga, en la ciudad no me hago yo, aunque ustedes no lo crean, me sentia mucho mejor (bis).

\section{Coro}

Allá en La Bonga, viví yo, quiero retornar, sí señor. Allá en La Bonga, viví yo, quiero retornar, si señor 


\section{VI}

Que me tratan de corroncho,

eso no me humilla a mi,

lo que le estoy contando,

es porque yo lo viví.

\section{Coro}

Allá en La Bonga, viví yo, quiero retornar, si señor.

Allá en La Bonga, vivi yo,

quiero retornar, si señor.

\section{Resultados}

\section{El territorio, sus carencias y sus riquezas}

De hecho, lo primero que salta a la vista es que el texto no informa explícitamente sobre el mundo experimentado en "La Bonga de San Rafael" en San Basilio de Palenque. Indagando en su contenido latente, emerge la idea de la negación del sujeto a describirse inscrito en otro territorio que no sea La Bonga; esto implica que quince años después del desplazamiento, en comparación con La Bonga, el territorio habitado hoy no es fuente de identidad para el sujeto.

En cuanto al contenido manifiesto, lo primero que se describe es una vida rural llena de carencias: 


\section{"Cuando yo vivia en La Bonga, en casa de bahareque y sin luz...". \\ "No tenía celular, tampoco televisor...".}

Entendiendo estas frases dentro del contexto socioeconómico del territorio, se evidencia una clara situación del abandono estatal, puesto que en toda la historia de la vereda nunca ha habido luz eléctrica, ni acueducto, ni saneamiento básico, ni puesto de salud, ni vías de acceso adecuadas, etc. Al respecto de esta interpretación, hay que aclarar que muy probablemente hacer esta denuncia no fue un propósito intencionado del compositor; pero como lo señala Thompson (1990):

Lo que el sujeto productor se propuso o quiso decir al producir la forma simbólica es ciertamente uno o algunos de estos factores y puede, en ciertas circunstancias, tener una importancia crucial... [Pero] sería muy engañoso sugerir que las intenciones del sujeto productor pudieran o debieran tomarse como la piedra angular de la interpretación (p. 208).

Sobre las carencias de electricidad o de medios de comunicación, que son las que se expresan directamente en el texto, no hay ningún asomo de queja; sugiriendo que no son necesidades sentidas para el compositor. De hecho, en entrevista personal, comentó que había solamente dos familias que se distinguían por poseer aparatos de televisión alimentados con energía solar; y que las fiestas se hacían con los "picó"14 que llegaban allá y traían su propia planta eléctrica ${ }^{15}$. Y tal como lo dice literalmente,

\section{"Las fiestas eran divinas,} porque eran hasta amanecer".

\footnotetext{
14 Equipos de sonido enormes que surgen y se popularizan en Barranquilla y Cartagena y que son utilizados para amenizar fiestas que convocan gran número de personas. Se caracterizan por su alto volumen.

15 Entrevista personal con Juan Herrera “El Futuro”. San Basilio de Palenque, 8 de julio de 2016.
} 
Igualmente, se infiere una vida campesina apacible, con abundancia y riquezas diferentes a los objetos suntuarios o al dinero en efectivo. La tierra y su cultivo son considerados el sustento de la vida, pero también fuente de identidad y tradición que son heredadas a las nuevas generaciones a través de la tradición oral,

"Vivía de mi cultivo, eso mi padre me enseñó, con eso me sustentaba, Una riqueza tenía yo".

Esta última idea es consistente con lo narrado por los bongueros participantes en el proyecto de memoria histórica: todos coinciden en considerar que ellos eran ricos en La Bonga, y esa riqueza se basaba en tener una casa y suficiente alimentación. Además, como parte de la vida comunitaria se compartían e intercambiaban los productos agropecuarios entre las familias, habiendo posibilidades de acumulación de productos para la comercialización en los poblados cercanos y en la ciudad de Cartagena, capital del departamento de Bolívar. Luego del desplazamiento, perdieron su fuente de sustento, fueron obligados a abandonar su tierra proveedora,

[...] fuera de La Bonga yo soy pobre de cien pesos, en cambio en mi Bonga yo tenía mis cultivos de ńame, mis animales, mis cerdos, pavos y así... yo era mayorista de ñame en el mercado de Cartagena... todo eso se perdió y he pasado hambre ${ }^{16}$.

\section{Cultivar la tierra y fortalecer el carácter}

El éxito de la vida en La Bonga radica en hacer producir la tierra, pero cuando se está por fuera de La Bonga, la fortaleza de carácter es parte de la técnica para sobrevivir como sujeto bonguero, en un nuevo mundo de experiencias.

16 Entrevista personal a una mujer; única persona, que junto a su esposo decidió volver a La Bonga sin ninguna garantía estatal. 
en Ciencias Sociales

"Vivia de mi cultivo,

eso mi padre me enseñó...".

Quien tiene tierra, la sabe cultivar y tiene la fuerza para hacerlo, se alimenta y alimenta a su familia. Y a pesar de que esta tierra ha sido agradecida produciendo sus frutos ${ }^{17}$, las condiciones en las que la población ha sacado sus productos históricamente, a lomo de bestias y a lomo de persona; y ahora, caminando hasta 4 horas diarias y sin caminos adecuados para sacar los frutos, no son las más adecuadas para aspirar a mejorar la calidad de vida de los bongueros, y mucho menos, para aspirar a hacer algún tipo de acumulación de capital. Es simplemente una economía de supervivencia.

Por otro lado, el texto también menciona que estando por fuera de La Bonga es necesario fortalecer el carácter para defender la identidad, que por el tiempo y la distancia, queda vulnerable a las afrentas del nuevo entorno, con el que al parecer, no hay ninguna intención de adaptarse y conformarse,

\section{"Que me tratan de corroncho, eso no me humilla a mí...". \\ "Quiero vivir en La Bonga, en la ciudad no me hago yo...".}

Por tanto, una forma de sobrevivir como bonguero en las actuales circunstancias, es recordar y narrar lo vivido para seguir viviendo: "Lo que le estoy contando es porque yo lo vivi". De hecho para Juan Herrera, recordar es vivir, especialmente mirando su presente $^{18}$.

17 Esta zona ha sido llamada "la despensa del Caribe".

18 Entrevista personal con Juan Herrera "El Futuro". San Basilio de Palenque, 8 de julio de 2016 


\section{Ser rico sin las condiciones básicas de la vida digna}

En cuanto a la valoración que hace el compositor de su mundo experimentado y rememorado, llaman la atención dos aspectos. En primer lugar, el hecho de que las carencias no sean expresadas como necesidades sentidas, sino como una condición inevitable para vivir en La Bonga, y sentirse bien,

\section{"Cuando yo vivia en La Bonga, \\ en casa de bahareque y sin luz, \\ las fiestas eran divinas, porque eran hasta amanecer". \\ "No tenía celular, \\ tampoco televisor, \\ aunque ustedes no lo crean, me sentía mucho mejor".}

Una posibilidad de interpretación consiste en asumir que la posición que ocupa el compositor en el campo de interacciones sociales, le lleva a utilizar cierto tipo de estrategias de valoración, que aunque no son exclusivas, son bastante usuales. En este caso, se entiende que el compositor y toda la comunidad desplazada de La Bonga, ocupan una posición devaluada, subordinada con respecto a las posiciones dominantes e intermedias, en el campo de las interacciones sociales. En esta posición se ubican aquellos sujetos individuales y colectivos que poseen muy pocos capitales, sin acumulación de riquezas, bajos niveles educativos y escaso reconocimiento social.

Ocupar esta posición implica que, por lo general, se centran en procurar la viabilidad de la vida misma, sus aspiraciones mayores les llevan a valorar objetos básicos para la vida diaria y no se interesan mayormente por otros valores agregados. Esta actitud de valorar la viabilidad del sobrevivir, en este caso, se vincula con una actitud de resignación respetuosa, tal como las denomina Thompson (1990). Es posible que 
tener electricidad, acueducto, saneamiento básico, atención médica, etc., pueden estarse considerando valores agregados y no condiciones necesarias para una vida digna, y a las que tienen derecho.

Esta interpretación no niega de ninguna manera que la población no haya solicitado la atención estatal en estos aspectos, pero hay que considerar al mismo tiempo que los mismos pobladores narran que lo conseguido hasta ahora ha sido por influencia política y no por razones de distribución equitativa de los recursos del Estado. No obstante, el texto analizado no expresa explícitamente esta actitud, sino que por el contrario, sugiere una resignación respetuosa.

En segundo lugar, el texto y la referencia que hace el compositor sobre la denominación de "ser rico" cuando se vivió en La Bonga, surge producto de las pérdidas y dańos sufridos con el desplazamiento, que le lleva a expresar permanentemente que "una riqueza tenía yo". Esto se comprende cuando dice:

Yo recuerdo eso 15 ańos atrás cuando para mí, el que tenía un celular era una persona rica, el que tenía buenos empleos en unas empresas, la televisión allá no se veía... y me sentía bien, nos sentíamos felices, contentos, a pesar de no tener celular, televisor..."19.

\section{Entre el deseo y la posibilidad}

El texto analizado denota un fuerte deseo por retornar a La Bonga. Las circunstancias del abandono de sus tierras y de las precarias condiciones en las que han tenido que vivir durante los últimos 15 ańos, les ha llevado a acrecentar enormemente su valoración del territorio, aun cuando no tenga las condiciones básicas para la vida digna. Este es el mayor motivo de añoranza. El deseo de retorno es el mensaje más recurrente de la composición musical, hay 4 estrofas y se repite el coro en 5 ocasiones. Es decir, la palabra retornar se repite 10 veces,

19 Entrevista personal con Juan Herrera “El Futuro". San Basilio de Palenque, 8 de julio de 2016. 


\section{"Allá en La Bonga, viví yo, \\ quiero retornar, sí señor. \\ Allá en La Bonga, vivi yo, \\ quiero retornar, si señor".}

Es claro que el retorno sintetiza el futuro deseado, y en eso es consistente con lo expresado por la mayoría de los participantes del proyecto. No obstante, la composición prefiere no arriesgar la descripción de un futuro posible. Y es que es un futuro que hasta el momento se ve algo borroso y lento, puesto que la concreción del retorno requiere condiciones especiales de reparación del daño, que hagan viable la vida digna en el territorio de La Bonga, y no solo en términos de justicia restaurativa, sino en términos de reparación transformadora (Uprimny y Saffón, 2009), que no les regrese únicamente a la situación en la que estaban al momento del desplazamiento, sino que también les lleve al gozo de los plenos derechos, que ni aún antes del desplazamiento se tenían. Y esto se evidencia también cuando Juan Herrera dice que la canción "es una invitación al retorno, porque yo quiero retornar a La Bonga como tal... con otras condiciones, no puede ser ahora lo mismo" 20 .

\section{ConClusiones}

El texto de la composición musical analizada describe un mundo premoderno lleno de carencias, en el que transcurre la vida campesina en el territorio de La Bonga. No obstante, se explicita que a pesar de las carencias, se vive una vida satisfactoria. Este hecho puede interpretarse como una actitud de resignación respetuosa, propia de la posición subordinada en la que se han formado estas comunidades históricamente.

Esta vida satisfactoria fue suspendida abruptamente por actores armados cuyo modus operandi fue la violencia llevada a extremos inimaginablemente crueles, con el propósito de fortalecer las posiciones históricamente dominantes. La consecuencia

20 Entrevista personal con Juan Herrera "El Futuro". San Basilio de Palenque, 8 de julio de 2016. 
de su paso por La Bonga fue el desplazamiento forzado de sus pobladores, a quienes no se les arrebató la tierra, pero al tener que abandonarla, perdieron el eje de su existencia, puesto que se toma consciencia de la riqueza poseída, de la vulnerabilidad de la identidad como bongueros.

Y si bien es cierto que son muchos los lazos comunitarios que se han roto, el deseo expresado en la composición musical de retornar al territorio propio es consistente con lo escuchado a muchos de los bongueros: el retorno se convierte en un propósito colectivo que moviliza voluntades y acciones, que aún distan mucho de ser colectivas.

La canción como artefacto de la memoria se convierte entonces en una oportunidad para reconstruir memorias colectivas, pero también como dispositivo para generar reflexión y cohesión social alrededor del territorio.

\section{REFERENCIAS}

Aguilera, M. (2013). Montes de María: una subregión de economía campesina y empresarial. Documentos de trabajo sobre economía regional. Núm. 195. Cartagena, Colombia: Banco de la República.

Arińo, A. (1997). Sociología de la cultura. Barcelona, España: Editorial Ariel.

Bayuelo, S. (2012). Memorias y relatos con sentidos 2008-2011: sistematización del proceso de memoria, territorio y comunicación. Bogotá D. C., Colombia: Colectivo de comunicaciones Montes de María Línea 21.

Beltrán Romero, C. H. y Vega Casanova, J. (2012). Aprendizajes sobre la evaluación del diálogo y el debate en estrategias de comunicación y cambio social. El caso de la Estrategia de Eduentretenimiento + Movilización Social $=$ Cambio Social. Investigación \& Desarrollo, 20(2), 390-415. Recuperado de http://www.redalyc.org/articulo.oa?id=26824854007 
Centro Nacional de Memoria Histórica. (2009). Recordar y narrar el conflicto. Herramientas para reconstruir memoria histórica. Bogotá D. C., Colombia: Imprenta Nacional de Colombia.

Centro Nacional de Memoria Histórica. (2013). ;Basta ya! Colombia: Memorias de Guerra y Dignidad. Informe General. Bogotá D. C., Colombia: Presidencia de la República.

Correa, Y. (2005). Creencias de los padres y madres que determinan el trato hacia los hijos e hijas en el asentamiento de La Pista, corregimiento de San Pablo (Maria La Baja - Bolivar) (trabajo de grado, Especialización en Prevención del Maltrato Infantil). Pontificia Universidad Javeriana, Cartagena, Colombia.

Departamento Administrativo Nacional de Estadística -DANE (2005). Censo 2005. Recuperado de http://www.dane.gov.co/index.php/esp/poblacion-y-registros-vitales/censos/ censo-200

De los Ríos, E., Becerra, C., Oyaga, F., y Sáenz, M. (2012). Montes de María. Entre la consolidación del territorio y el acaparamiento de tierras. Aproximación a la situación de DD. HH. y del DIH en la región (2006-2012). Bogotá D. C., Colombia: ILSA.

Giddens, A. (1997). Las nuevas reglas del método sociológico. 2a edición. Buenos Aires, Argentina: Amorrortu.

Lifschitz, J. y Arenas, S. (2012). Memoria política y artefactos culturales. Estudios Políticos, (40), 98-119. Instituto de Estudios Políticos, Universidad de Antioquia. Recuperado de http://www.scielo.org.co/pdf/espo/n40/n40a05.pdf

Melot, M. (2008). El libro como forma simbólica. Enl@ce: Revista Venezolana de Información, Tecnología y Conocimiento, 5(3), 129-139.

Mosterín, J. (1993). La filosofía de la cultura. Madrid, España: Alianza Editorial. 
Rodríguez, C. (2008). Lo que le vamos quitando a la guerra. Bogotá D. C., Colombia: Centro de Competencia en Comunicación. Recuperado de http://library.fes.de/pdf-files/bueros/c3-comunicacion/07330.pdf

Therborn, G. (1987). La ideología del poder y el poder de la ideología. Madrid, España: Siglo Veintiuno Editores.

Thompson, J. (1990). Ideología y cultura moderna. México D. F., México: UNAM - X.

Uprimny, R. y Saffón, M. (2009). Reparaciones transformadoras, justicia distributiva y profundización democrática. En Díaz, C., Sánchez, N., y Uprimny, R. (Eds.), Reparar en Colombia. Los dilemas en contextos de conflicto, pobreza y exclusión (pp. 31-70). Bogotá D. C., Colombia: ICTJ Dejusticia.

Valencia, D. (2014). El síndrome de Korsakov. Editorial de la revista Conmemora, $3^{\text {a }}$ edición. http://www.centrodememoriahistorica.gov.co/destacados-cnmh/conmemora-destacado

Vargas, G. (2003). Tratado de epistemología, fenomenología de la ciencia, la tecnología y la investigación social. Bogotá D. C., Colombia: Sociedad de San Pablo. 